\title{
In Vivo Imaging-Based Techniques for Early Diagnosis of Oral Potentially Malignant Disorders-Systematic Review and Meta-Analysis
}

\author{
Marta Mazur ${ }^{1}\left(\mathbb{D}\right.$, Artnora Ndokaj ${ }^{1, * \mathbb{D}}$, Divyambika Catakapatri Venugopal ${ }^{2} \mathbb{D}$, Michela Roberto ${ }^{3} \mathbb{D}$,

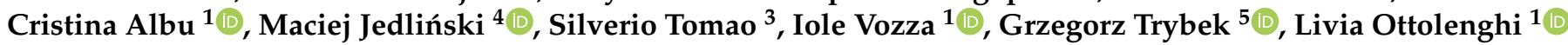 \\ and Fabrizio Guerra 1
}

check for updates

Citation: Mazur, M.; Ndokaj, A.; Venugopal, D.C.; Roberto, M.; Albu, C.; Jedliński, M.; Tomao, S.; Vozza, I.; Trybek, G.; Ottolenghi, L.; et al. In Vivo Imaging-Based Techniques for Early Diagnosis of Oral Potentially Malignant Disorders-Systematic Review and Meta-Analysis. Int. J. Environ. Res. Public Health 2021, 18, 11775. https://doi.org/10.3390/ ijerph182211775

Academic Editor: Takaaki Tomofuji

Received: 28 September 2021 Accepted: 8 November 2021 Published: 10 November 2021

Publisher's Note: MDPI stays neutral with regard to jurisdictional claims in published maps and institutional affiliations.

Copyright: (c) 2021 by the authors. Licensee MDPI, Basel, Switzerland. This article is an open access article distributed under the terms and conditions of the Creative Commons Attribution (CC BY) license (https:/ / creativecommons.org/licenses/by/ $4.0 /)$.
1 Department of Oral and Maxillo-Facial Sciences, Sapienza University, 00161 Rome, Italy; marta.mazur@uniroma1.it (M.M.); albu.1811182@studenti.uniroma1.it (C.A.); iole.vozza@uniroma1.it (I.V.); livia.ottolenghi@uniroma1.it (L.O.); fabrizio.guerra@uniroma1.it (F.G.)

2 Department of Oral Medicine and Radiology, Faculty of Dental Sciences, Sri Ramachandra Institute of Higher Education and Research, Chennai 600116, India; cvdivyambika@sriramachandra.edu.in

3 Medical Oncology Unit, Department of Radiological, Oncological and Anatomo-Pathological Sciences, Sapienza University, 00161 Rome, Italy; michela.roberto@uniroma1.it (M.R.); silverio.tomao@uniroma1.it (S.T.)

4 Department of Interdisciplinary Dentistry, Pomeranian Medical University in Szczecin, 70111 Szczecin, Poland; maciej.jedlinski@pum.edu.pl

5 Department of Oral Surgery, Pomeranian Medical University in Szczecin, 70111 Szczecin, Poland; g.trybek@gmail.com

* Correspondence: artnora.ndokaj@uniroma1.it

\begin{abstract}
Objectives: Oral potentially malignant disorders (OPMDs) are lesions that may undergo malignant transformation to oral cancer. The early diagnosis and surveillance of OPMDs reduce the morbidity and mortality of patients. Diagnostic techniques based on medical images analysis have been developed to diagnose clinical conditions. This systematic review and meta-analysis aimed to evaluate the efficacy of imaging-based techniques compared to the gold standard of histopathology to assess their ability to correctly identify the presence of OPMDs. Design: Literature searches of free text and MeSH terms were performed using MedLine (PubMed), Scopus, Google Scholar, and the Cochrane Library (from 2000 to 30 June 2020). The keywords used in the search strategy were: ("oral screening devices" or "autofluorescence" or "chemiluminescence" or "optical imaging" or "imaging technique") and ("oral dysplasia" or "oral malignant lesions" or "oral precancerosis"). Results: The search strategy identified 1282 potential articles. After analyzing the results and applying the eligibility criteria, the remaining 43 papers were included in the qualitative synthesis, and 34 of these were included in the meta-analysis. Conclusions: None of the analyzed techniques based on assessing oral images can replace the biopsy. Further studies are needed to explore the role of techniques-based imaging analysis to identify an early noninvasive screening method.
\end{abstract}

Keywords: imaging-based techniques; potentially malignant oral lesions; OPMD; diagnosis

\section{Introduction}

Oral potentially malignant disorders (OPMDs) are precursor lesions that may undergo malignant transformation to oral cancer. These lesions most commonly present clinically as white patches (leukoplakia). However, they may be red (erythroplakia) or red and white (erythroleukoplakia). Oral submucous fibrosis (OSMF) is another common OPMD seen predominantly in Southeast Asia and more commonly in the Indian subcontinent, presenting with severe burning sensation, blanching of the oral mucosa, and trismus due to fibrotic bands. OSMF is attributed to the use of areca nut, and it has been estimated that around $10-20 \%$ of the world population use areca nut in different formulations [1-3]. 
Currently, tobacco and areca nut usage in a variety of commercial preparations has led to an increase in the prevalence of OPMDs. The worldwide prevalence rate of OPMDs ranges from 1 to $5 \%[4,5]$.

Since India contributes to one-third of the global oral cancer burden, it is considered the world capital for oral cancer. Southern parts of India present the highest incidence rate of oral cancer among females both nationally and globally. The high financial burden for the patients undergoing oral cancer treatment leads to treatment breaks, thus adding further to the mortality rate [6]. The increased incidence of OPMDs and Oral Squamous Cell carcinoma (OSCC) in the Indian subcontinent is mainly attributed to the prevalence of tobacco usage among varied age groups. Apart from various forms of tobacco, chewing paan with areca nut contributes to oral malignancy, especially in the northeastern parts of India, leading to the high incidence of OSCC [7]. Global Adult Tobacco Survey (GATS) uses a standard and globally accepted protocol for monitoring adult smoking and smokeless tobacco use across countries, including India. According to the GATS 2 Fact Sheet, India 2016-2017, $42.4 \%$ of men, $14.2 \%$ of women, and 266.8 million of all adults currently use either smoking or smokeless forms of tobacco. One out of every eight young individuals 15 to 24 years old was using tobacco in any formulation.

Approximately $16-62 \%$ of OPMDs undergo a malignant transformation and eventually develop into oral squamous cell carcinoma (OSCC). OSCC is the most common oral cancer, representing more than $90 \%$ of all oral cancers. The five-year survival rates of OSCC patients decrease from 80 to $40 \%$ between diagnosis at an early or advanced stage [8]. Despite current advances in treatment, the 5-year survival rate for oral cancer has not increased substantially during the past several decades. The lack of effective early detection of high-risk OPMDs is one of the critical reasons for the poor prognosis of OSCC [9]. Treatment is more effective in patients with the early stage of disease; however, most patients present with advanced tumors for which treatment is less successful and may cause severe deficits in speech, swallowing, facial appearance, and quality of life [10].

The early diagnosis and surveillance of OPMDs reduce morbidity and mortality in OSCC patients. The early identification of dysplasia helps the clinician monitor the patients periodically and plays an important role in detecting oral carcinogenesis, improving the survival rate, and reducing disfigurement, loss of function, treatment duration, and the associated treatment expenditure, especially in developing countries worldwide [8].

Oral tissue biopsy is the gold standard for the diagnosis of OPMDs. However, this procedure is: (i) locally invasive; (ii) hardly acceptable by patients; (iii) time-consuming with no immediate results; (iv) primarily available in hospitals; and (v) not suitable for OPMDs long-term monitoring [11].

In this clinical scenario, diagnostic techniques based on medical images analysis have been developed using different approaches of artificial intelligence. They have been employed in different medical fields to detect, for instance, breast cancer in mammography, skin cancer in clinical skin screenings, diabetic retinopathy, in retinographies of periodontal bone loss on periapical and panoramic radiographs, and apical lesions and caries lesions on periapical radiographs. In oral pathology, several image-based techniques have been developed to detect OPMDs, the autofluorescence, high-resolution microendoscope (HRME), optical spectroscopy, narrow band imaging and vital staining colorants, among others [12-16].

These techniques are non-invasive, highly accepted and tolerated by patients, available in all clinical settings, non-operator-dependent, and repeatable [4,17-23].

Therefore, this systematic review and meta-analysis aimed to evaluate the efficacy of imaging-based techniques compared to the gold standard of histopathology in order to assess the ability of the imaging-based techniques to correctly identify the presence of OPMDs. 


\section{Materials and Methods}

This systematic review was conducted according to the PRISMA (Preferred Reporting Items for Systematic Reviews and Meta-Analyses) statement and the guidelines from the Cochrane Handbook for Systematic Reviews of Interventions. The study protocol was registered after the screening stage (PROSPERO CRD42021230814).

\subsection{Eligibility Criteria}

The following inclusion criteria were applied to this meta-analysis: (a) randomized clinical trials (RCTs); (b) clinical trials; (c) cohort studies; (d) cross-sectional studies; (e) casecontrol studies; (f) pilot studies; (g) prospective and observational studies; (h) all considered participants were patients with suspicious oral lesions, a history of previously treated OSCC (Oral Squamous Cell Carcinoma) with no current evidence of cancer recurrence at least six months after cessation of treatment, or the presence of recently diagnosed, untreated OSCC or precancerous lesions; (i) the control intervention considered healthy volunteers without any oral abnormalities; (j) studies published in English, French, German, Spanish, Polish, Albanian, and Romanian. Broad inclusion criteria have been used to be as sensitive as possible. Exclusion criteria were as follows: (a) in vitro RCTs; (b) lack of effective statistical analysis; (c) abstract and author debates or editorials.

The outcomes to be assessed are listed as follows: sample size; oral lesions; presence or absence of biopsy; analyzed techniques for detection of mucosa alteration; strengths and weakness of each analyzed technique; measures: accuracy, sensitivity, specificity, positive predictive value, and negative predictive value.

\subsection{Search Strategy and Study Selection}

Literature searches of free text and MeSH terms were performed using PubMed, Scopus, Google Scholar, and the Cochrane Library (from 2000 to 30 June 2020). All searches were conducted using a combination of subject headings and free-text terms. The final search strategy was determined through several presearches. The keywords used in the search strategy were as follows: ("oral screening devices" or "autofluorescence" or "chemiluminescence" or "optical imaging" or "imaging technique") and ("oral dysplasia" or "oral malignant lesions" or "oral precancerosis").

The detailed search strategy used in PubMed, Scopus, Google Scholar, and the Cochrane Library are illustrated in Figure 1.

Reference lists of primary research reports were cross-checked to identify additional studies. Following the inclusion criteria, two authors (CA and AN) independently selected the literature by reading the titles and abstracts. The full text of each identified article was then read to determine whether it was suitable for inclusion. Disagreements were resolved through consensus or by a discussion with a third author (MM).

\subsection{Data Collection}

For each eligible study, data were independently extracted by two authors (CA and $\mathrm{AN}$ ) and examined by the third author (MM). The data were compared through a created piloted spreadsheet, according to the Cochrane Collaboration guidelines. In case of missing data, MM contacted the corresponding author of the related research via e-mail and excluded those for which no reply was given.

\subsection{Data Items}

The following data items were recorded: study year, type and setting; age, size, and recruitment sample; case and control interventions; any pre-treatment and co-intervention; biopsy; analyzed technique; washout period in RCTs with crossover design; the follow-up, dropout and sample size at follow-up. 


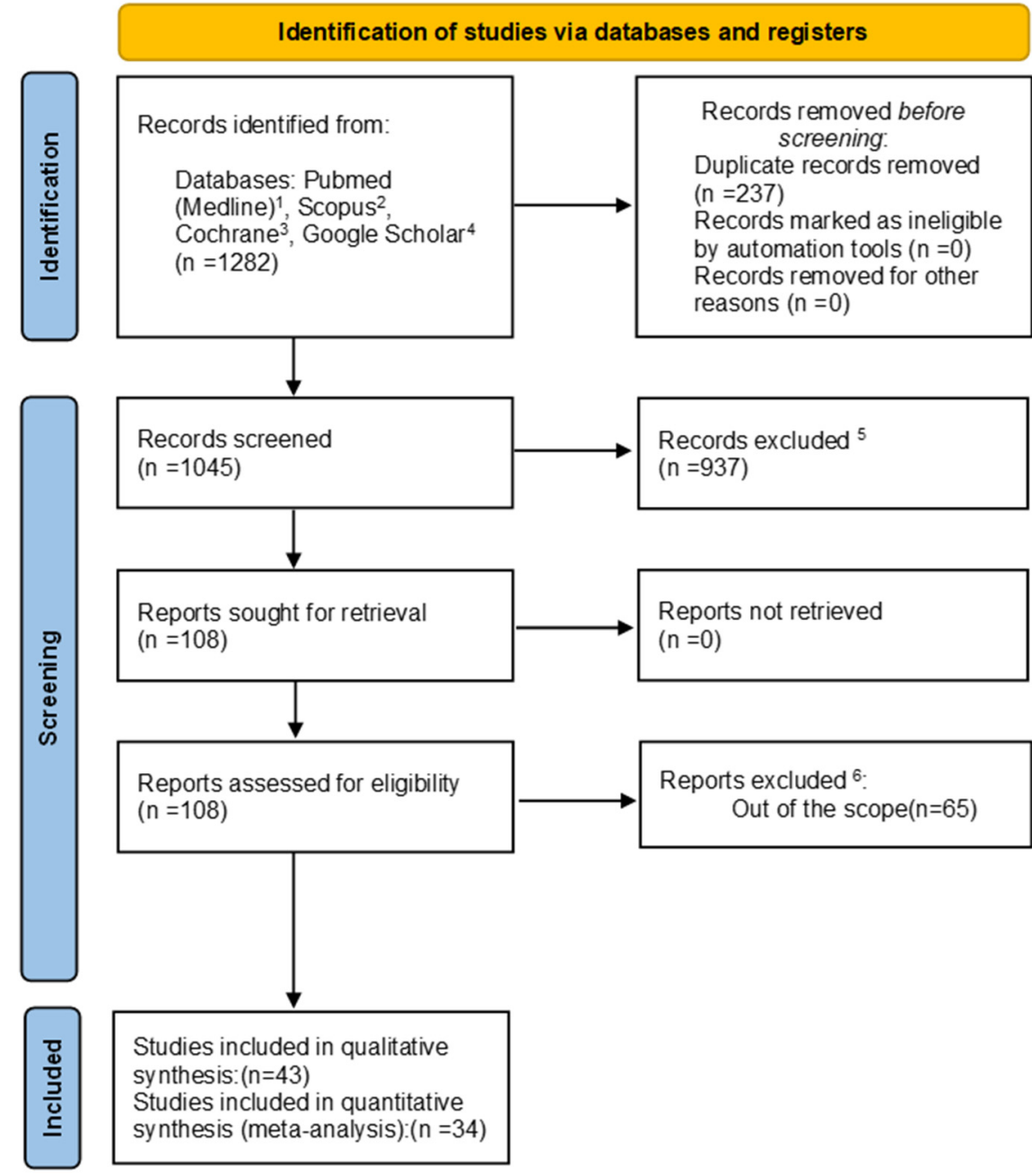

1. search string: [("oral screening devices" OR "autofluorescence" OR "chemiluminescence" OR "optical imaging" OR "imaging technique") AND ("oral dysplasia" OR "oral malignant lesions" OR "oral precancerosis")].

2-search string: TITLE-ABS-KEY ("oral screening devices" OR "autofluorescence" OR "chemiluminescence" OR "optical imaging" OR "imaging technique" AND "oral dysplasia" OR "oral malignant lesions" OR "oral precancerosis").

${ }^{3}$-search string: ("oral screening devices" OR "autofluorescence" OR "chemiluminescence" OR "optical imaging" OR "imaging technique" AND "oral dysplasia" OR "oral malignant lesions" OR "oral precancerosis") in Title Abstract Keyword.

4-search string: [("oral screening devices" OR "autofluorescence" OR "chemiluminescence" OR "optical imaging" OR "Imaging technique") AND ("oral dysplasia" OR "oral malignant lesions" OR "oral precancerosis")].

${ }^{5}$-because not relevant to the subject, author's debates, lack of effective statistical analysis, case reports, incomplete studies, reviews, in-vitro studies.

${ }^{6}$ - because not relevant to the full-text analysis

Figure 1. The flowchart of the search.

\subsection{Quality Assessment}

According to the PRISMA statements, the evaluation of the methodological quality indicates the strength of evidence provided by the study because methodological flaws can result in biases. For the randomized clinical trials, according to the Jadad scale, this procedure provides a total score that can range from 0 to 5 , where 0 is a low-quality study, and 5 is the highest possible quality. A trial is considered to have a good quality when it receives a score of at least 3 . For cross-sectional, case-control, and cohort studies, according to the Newcastle-Ottawa scale (NOS), the possible quality assessment score ranges from 0 to 9 points, with a high score indicating a good quality study. 


\subsection{Risk of Bias in Individual Studies}

Selection bias (retained allocation concealment), performance and detection bias (blinding of participants and operators), attrition bias (patient dropout, washout period of crossover trials and missing values or participants, too short a duration of follow-up), and reporting bias (selective reporting, unclear eliminations, missing results) were recorded, evaluated, and allocated according to Cochrane guidelines [24].

\subsection{Consistency Measures and Risk of Bias across Studies}

Heterogeneity was assessed quantitatively using I2 170-statistics and Cochran's $Q$ test [25]. The high percentage of variability comes from the heterogeneity of samples among studies. Funnel plot analyses were performed to assess small study effects or publication bias for analyses with two or more studies being present.

\section{Results}

\subsection{Study Selection}

The search strategy identified 1282 potential articles: 200 from PubMed, 18 from Scopus, 344 from Cochrane, and 720 from Google Scholar. After the removal of duplicates, 1045 articles were analyzed.

Subsequently, 937 papers were excluded because they did not meet the inclusion criteria. Of the remaining 108 papers, 65 were excluded because they were not relevant to the subject of the study. The remaining 43 papers were included in the qualitative synthesis, and 34 of these were included in the meta-analysis (Figure 1). Table 1 summarizes the characteristics of each of the 34 included studies. All the included papers reported odd ratio (OR) for the study's relevant query data.

Meta-analysis was carried out for the sensitivity of techniques. Results were divided into five groups of used techniques: autofluorescence, HRME, optical spectroscopy, narrow band imaging, vital staining colorants. Meta-analysis was performed using a randomeffect model. Effect sizes were calculated based on numbers of "Biopsy positive" and "Sample size positive (with biopsy positive)" true positives. The risk difference (RD) was taken as an effect size assuming zero risk of biopsy measurement. Heterogeneity was assessed quantitatively using I2 170 -statistics and Cochran's Q-test [25]. Meta-analysis for the specificity of techniques was not carried out because false positives were only available for a few studies. Reported specificity and other characteristics were often calculated relative to techniques other than biopsy or a larger group, making results incomparable. The R statistical program (The R Foundation for Statistical Computing, Wirtschaftsuniversität Wien, Vienna, Austria) with compute.es and metaphor packages was used for the calculations [26,27].

\subsection{Study Characteristics}

Included studies (Table 1) were published between 2006 and 2020, and they were focused on the Autofluorescence technique (n:14) [28-41], HRME (n:5) [42-46], Optical spectroscopy (n:7) [10,47-52], NBI (n:2) [53,54], and Vital Stain Colorants (n:6) [55-60]. In total, 34 studies were performed in adults (18 years of age or older). Sample sizes ranged between 4 and 200 participant sites (mean: 82), for an overall sample size of 2792. Each technique was compared to the golden standard: tissue histology that always guarantees $100 \%$ diagnosis. 
Table 1. Characteristics of included studies.

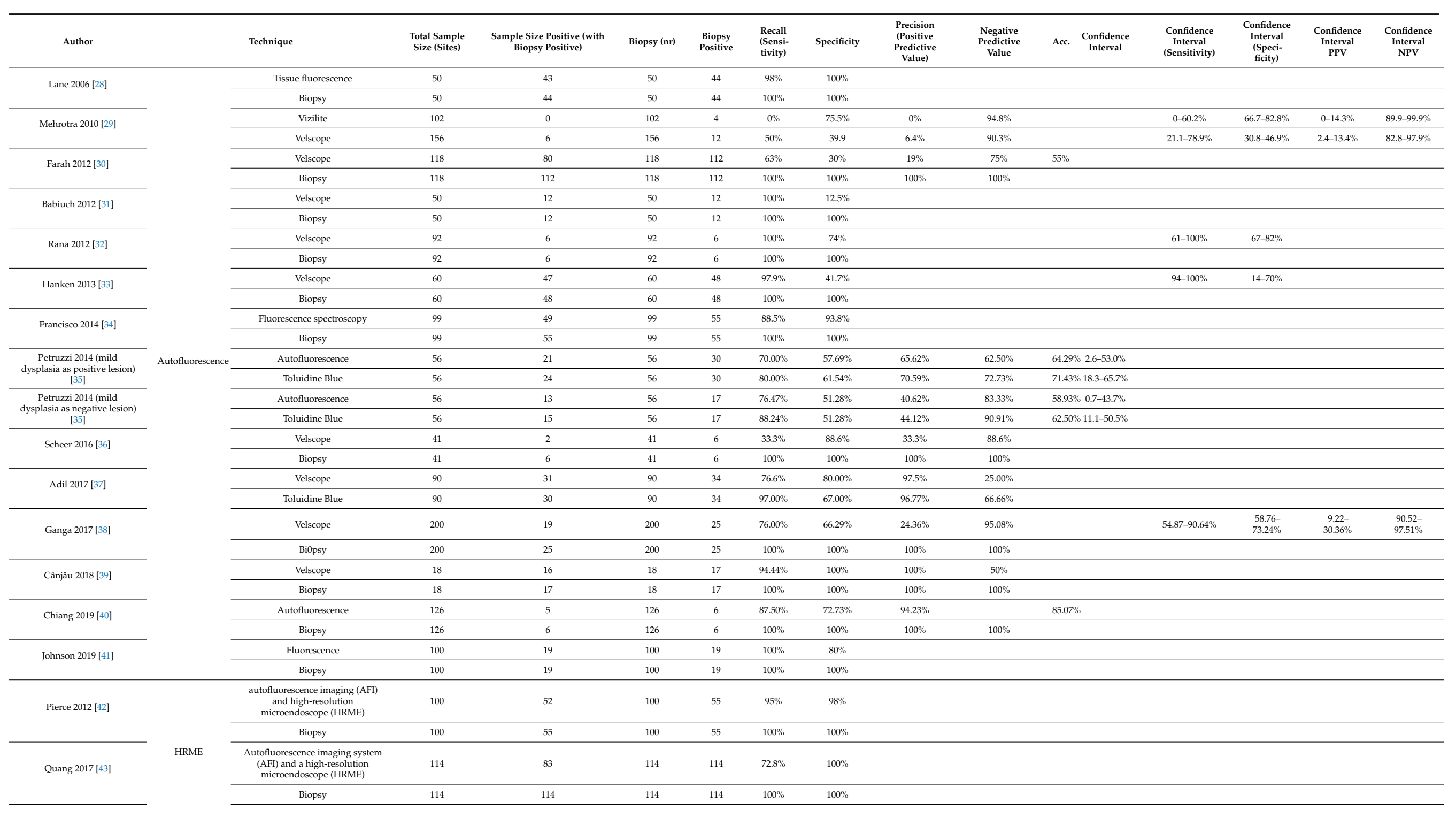


Table 1. Cont.

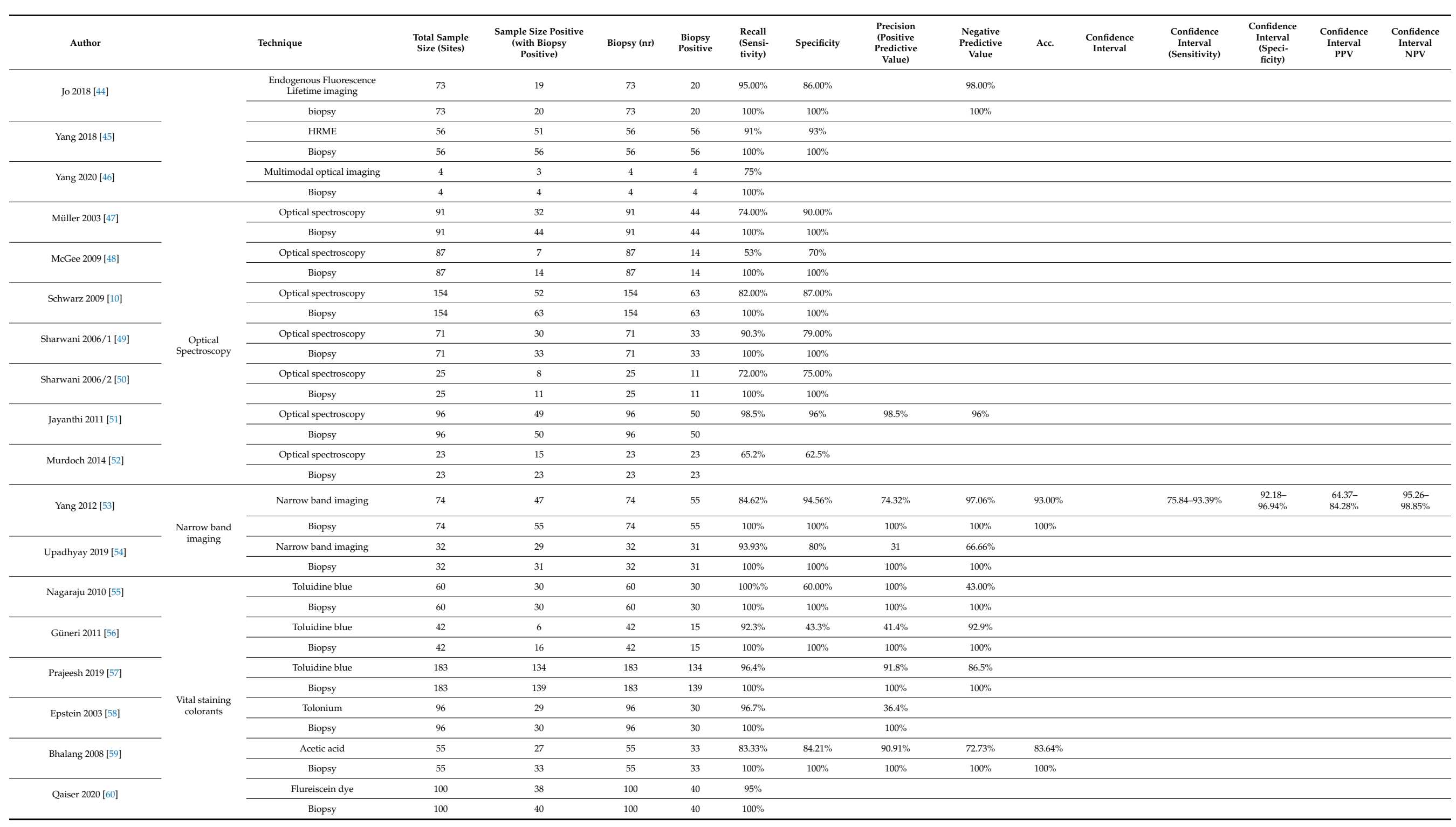




\subsubsection{Autofluorescence}

Autofluorescence is one potential technique that may be used to facilitate the visualization of OPMD and oral cancer. Autofluorescence works on the principle that certain biofluorophores present within the tissue become fluorescent on excitation with a suitable wavelength (400-460 nm) light source. The diseased tissues tend to appear darker since they lose fluorescence, which is attributed to the disruption in the distribution of the biofluorophores [61]. In the present study, the image-based techniques based on autofluorescence were: Vizilite and VELScope. Wide-field imaging devices, such as the VELScope, can survey large mucosal surface areas to detect regions with loss of autofluorescence, which is suspicious for dysplasia.

\subsubsection{High-Resolution Microendoscopy (HRME)}

The high-resolution microendoscope (HRME) uses a coherent fiber bundle to obtain high-resolution fluorescence images of the tissue in contact with the distal tip of the device without the need for complex mechanical scanning systems and associated control electronics. The system uses a low-cost light-emitting diode to provide illumination and a consumer-grade charge-coupled device camera to capture high-resolution digital images on a laptop computer $[62,63]$. HRME is usually used together with autofluorescence imaging (AFI) because HRME devices can complement these types of wide-field imaging systems by providing high-resolution image data at specific lesions first identified by loss of fluorescence [64].

\subsubsection{Optical Spectroscopy}

Optical spectroscopy can be used to detect changes in oral mucosa during carcinogenesis in the oral cavity, based on the fact that increased nuclear size and nuclear to cytoplasmic ratio, increased microvascularization, degradation of stromal collagen, and alterations in the concentration of mitochondrial fluorophores such as reduced nicotinamide adenine dinucleotide (NADH) and flavin adenine dinucleotide (FAD) affect the optical scattering, absorption, and autofluorescence characteristics within the tissue. Spectroscopic measurements are usually performed in a darkened room to minimize the effects of ambient light. The optical spectroscopy autofluorescence spectra are characterized by 12 excitation wavelengths ranging from 300-470 nanometers $(\mathrm{nm})$ and a diffuse reflectance spectrum under white light illumination that can be collected through each of four probe channels with different depth responses, for a total of 52 spectra collected in each 90 s measurement. The shallow channel has a depth response weighted toward the epithelial tissue layer; the medium channel interrogates both epithelium and shallow stroma, and the two deep channels collect signals primarily from the stroma [10].

\subsubsection{Narrow Banding Imaging}

Narrow band imaging (NBI) is an endoscopic technique based on the use of special optical filters that narrow the light bandwidth to enhance the visualization of the mucosa surface and microvasculature [65]. NBI associated with a magnification zoom facility is useful for the accurate diagnosis of early cancers due to the contrast observation of vascular architecture, particularly the intrapapillary capillary loops (IPCL) [65]. In neoplastic lesions, the IPCL are modified by dilation, meandering, and caliber irregularities that can be differentiated from normal mucosa. Morphological changes to the IPCL are useful for diagnosing early cancers and determining the depth of invasion [66] and the margin of resection $[67,68]$.

\subsubsection{Vital Stain Colorants}

The vital colorants have been used as diagnostic aids since the early 1980s. The changes that characterize dysplastic and malignant cells (disordered arrangement, loose connections, more nucleic acid than normal cells) allow the colorants to enter the extracellular space and bind the intracellular nucleic acid making the tissue distinguished [69]. This study report 
results mainly on toluidine blue, tolonium, acetic acid, and fluorescein dye. Toluidine blue stain could serve as an adjunct during clinical examination for recognition of suspicious lesions which could undergo malignant transformation [70]. Vital staining techniques also aid in choosing the appropriate site for biopsy of both large lesions and when there is multiple site involvement and has been suggested to be an effective screening tool, especially in high-risk cases [71]. Although some of the potential disadvantages include the interpretation of faintly positive cases, adequate training and colour guide may help overcome the disadvantages, thereby improving the sensitivity and specificity [72].

\subsection{Quality Assessment}

According to the Jadad scale for RCT, the authors evaluated the quality of one clinical trial [33] included in the qualitative synthesis, based on five questions that analyze the randomization process, the experimental blinding, and the dropout rate, i.e., the patients lost to follow-up. In evaluating the quality of RCTs, the total score of this study was 3, indicating a good quality study (Table 2).

Table 2. Jadad Scale for randomized control trials.

\begin{tabular}{cc}
\hline \multicolumn{1}{c}{ Jadad Scale for Reporting Randomized Controlled Trials } \\
\hline $\begin{array}{c}\text { (1) Is the study described as randomized? } \\
\text { (2) Is the study described as double-blind? }\end{array}$ & 1 \\
\hline $\begin{array}{c}\text { (3) Is there a description of withdrawals and } \\
\text { dropouts? }\end{array}$ & 0 \\
\hline $\begin{array}{c}\text { (4) The method of randomization is } \\
\text { appropriate? }\end{array}$ & 1 \\
\hline (5) The method of blinding is appropriate? & 3 \\
\hline Total score=
\end{tabular}

According to the Newcastle-Ottawa scale (NOS) on cross-sectional (n:24) $[28,29,31$, $35,37,39,40,42-46,48-50,54-56,59,60,73-76]$; case-control (n:10) [10,32,47,51-53,77-80] and cohort studies (n:7) $[30,34,36,38,41,57,58]$ the authors evaluated the qualities of all included studies based on object selection, comparability, and exposure. A star was described as an appropriate entry, with each star representing one point. The possible quality assessment score ranged from zero to nine points, with a high score indicating a good quality study. In evaluating the quality of cross-sectional studies, the total scores of two studies were lower or equal to five, indicating low-quality studies, while the total scores of the other twenty-two were six or higher, indicating medium or high-quality studies (Table 3). For the case-control studies, the total scores of three studies were lower or equal to five, indicating low-quality studies, while the total scores of the other seven were six or higher, indicating medium or high-quality studies (Table 4). While the quality of cohort studies, the total score of all included studies, except for one, was greater than or equal to 6 , indicating high-quality studies (Table 5).

\subsection{Effect Size}

A comparison of studies is shown on the forest plot (Figure 2). Using of techniques has a small negative effect size of 81 in all five groups: from- 0.10 in narrow band imaging and Vital staining colorants groups to- 0.20 in the optical spectroscopy group. There are no significant differences in RD between groups (minimum p-value equals 0.28 in Welch's two sample $t$-tests). 
Table 3. Newcastle-Ottawa Scale adapted for cross-sectional studies.

\begin{tabular}{|c|c|c|c|c|c|c|c|c|c|c|c|c|c|c|c|c|c|c|c|c|c|c|c|c|c|}
\hline \multicolumn{26}{|c|}{ Newcastle-Ottawa Scale Adapted for Cross-Sectional Studies } \\
\hline & & $\begin{array}{c}\text { Ambele } \\
2020 \\
{[73]}\end{array}$ & $\begin{array}{l}\text { Cânjău } \\
2018 \\
\text { [39] }\end{array}$ & $\begin{array}{l}\text { Mehrotra } \\
2010 \\
{[29]}\end{array}$ & $\begin{array}{l}\text { Adil } \\
2017 \\
{[37]}\end{array}$ & $\begin{array}{c}\text { Babiuch } \\
2012 \\
{[31]}\end{array}$ & $\begin{array}{l}\text { Ikeda } \\
2020 \\
{[74]}\end{array}$ & $\begin{array}{l}\text { Poh } \\
2007 \\
\text { [75] }\end{array}$ & $\begin{array}{l}\text { Lane } \\
2006 \\
{[28]}\end{array}$ & $\begin{array}{c}\text { Chiang } \\
2019 \\
{[40]}\end{array}$ & $\begin{array}{l}\text { Yang } \\
2018 \\
{[45]} \\
\end{array}$ & $\begin{array}{c}\text { Pierce } \\
2012 \\
{[42]}\end{array}$ & $\begin{array}{l}\text { Yang } \\
2020 \\
{[46]}\end{array}$ & $\begin{array}{c}\text { Jo } 2018 \\
\text { [44] }\end{array}$ & $\begin{array}{c}\text { McGee } \\
2009 \\
{[48]}\end{array}$ & $\begin{array}{l}\text { Sharwani } \\
2006 \\
{[49]}\end{array}$ & $\begin{array}{l}\text { Sharwani } \\
2006 \\
{[50]}\end{array}$ & $\begin{array}{l}\text { Upadhyay } \\
\text { 2019 } \\
\text { [54] }\end{array}$ & $\begin{array}{c}\text { Petruzzi } \\
2014 \\
{[35]}\end{array}$ & $\begin{array}{c}\text { Bhalang } \\
2009 \\
{[59]}\end{array}$ & $\begin{array}{l}\text { Güneri } \\
2011 \\
{[56]}\end{array}$ & $\begin{array}{l}\text { Nagaraju } \\
2010 \\
{[55]}\end{array}$ & $\begin{array}{l}\text { Fakurnejad } \\
2019 \\
{[76]}\end{array}$ & $\begin{array}{l}\text { Qaiser } \\
2020 \\
{[60]}\end{array}$ & $\begin{array}{l}\text { Quans } \\
2017 \\
{[43]}\end{array}$ \\
\hline \multirow{4}{*}{$\begin{array}{l}\text { Selection: } \\
\text { (Maximum } \\
5 \text { stars) }\end{array}$} & $\begin{array}{l}\text { (1) Represen- } \\
\text { tativeness of } \\
\text { the sample }\end{array}$ & & & * & $*$ & & * & & * & * & & * & * & * & * & * & & & & & & & & & * \\
\hline & $\begin{array}{c}\text { (2) Sample } \\
\text { size }\end{array}$ & & & * & & & * & & * & * & & & * & & * & * & & * & & & * & & & & $*$ \\
\hline & $\begin{array}{c}\text { (3) Non- } \\
\text { respondents }\end{array}$ & * & * & * & * & * & * & * & * & * & * & * & * & * & * & & * & * & * & * & & & * & & * \\
\hline & $\begin{array}{l}\text { (4) Ascertain- } \\
\text { ment of the } \\
\text { exposure (risk } \\
\text { factor) }\end{array}$ & ** & $* *$ & $* *$ & $*$ & $*$ & $* *$ & ** & $*$ & $* *$ & $* *$ & $* *$ & ** & $*$ & $* *$ & $*$ & $*$ & $*$ & $*$ & $*$ & ** & ** & ** & $* *$ & $* *$ \\
\hline $\begin{array}{l}\text { Comparability: } \\
\text { (Maximum } \\
\text { 2 stars) }\end{array}$ & $\begin{array}{l}\text { (5) The } \\
\text { subjects in } \\
\text { different } \\
\text { outcome } \\
\text { groups are } \\
\text { comparable, } \\
\text { based on the } \\
\text { study design } \\
\text { or analysis. } \\
\text { Confounding } \\
\text { factors are } \\
\text { controlled. }\end{array}$ & * & * & * & ${ }^{*}$ & * & * & * & * & * & $*$ & * & * & * & * & * & * & * & * & * & * & * & * & * & * \\
\hline \multirow{2}{*}{$\begin{array}{l}\text { Outcome: } \\
\text { (Maximum } \\
\text { s stars) }\end{array}$} & $\begin{array}{c}\text { (6) } \\
\text { Assessment of } \\
\text { the outcome }\end{array}$ & $* *$ & $*$ & $* *$ & $* *$ & $* *$ & $* *$ & ** & $*$ & $* *$ & $* *$ & $* *$ & $* *$ & $* *$ & $* *$ & $* *$ & $* *$ & $*$ & $* *$ & ** & $* *$ & $* *$ & ** & $*$ & $* *$ \\
\hline & Total score= & 6 & 6 & 8 & 8 & 6 & 9 & 6 & 8 & 9 & 6 & 7 & 8 & 7 & 8 & 8 & 6 & 8 & 7 & 7 & 6 & 5 & 7 & 5 & 9 \\
\hline
\end{tabular}


Table 4. Newcastle-Ottawa quality assessment scale case-control studies.

\begin{tabular}{|c|c|c|c|c|c|c|c|c|c|c|c|}
\hline \multicolumn{12}{|c|}{ Newcastle-Ottawa Quality Assessment Scale Case-Control Studies } \\
\hline & & $\begin{array}{l}\text { Poh } \\
2016 \\
{[77]}\end{array}$ & $\begin{array}{c}\text { Rana } \\
2012 \\
{[32]}\end{array}$ & $\begin{array}{l}\text { Huff } \\
2009 \\
{[78]}\end{array}$ & $\begin{array}{l}\text { Schwarz } \\
2009 \\
{[10]}\end{array}$ & $\begin{array}{c}\text { Jayanthi } \\
2011 \\
{[51]}\end{array}$ & $\begin{array}{l}\text { Murdoch } \\
2014 \\
{[52]}\end{array}$ & $\begin{array}{c}\text { Mallia } \\
2010 \\
{[79]}\end{array}$ & $\begin{array}{c}\text { Müller } \\
2003 \\
{[47]}\end{array}$ & $\begin{array}{l}\text { Yang } \\
2012 \\
{[53]}\end{array}$ & $\begin{array}{l}\text { Vijayavel } \\
2013 \\
{[80]}\end{array}$ \\
\hline \multirow{4}{*}{$\begin{array}{l}\text { Selection: } \\
\text { (Maximum } 4 \\
\text { stars) }\end{array}$} & $\begin{array}{l}\text { (1) Is the } \\
\text { case defi- } \\
\text { nition } \\
\text { ade- } \\
\text { quate? }\end{array}$ & $*$ & * & * & * & $*$ & * & * & * & * & * \\
\hline & $\begin{array}{l}\text { (2) Rep- } \\
\text { resenta- } \\
\text { tiveness } \\
\text { of the } \\
\text { cases }\end{array}$ & $*$ & * & $*$ & * & $*$ & * & & & * & * \\
\hline & $\begin{array}{l}\text { (3) Selec- } \\
\text { tion of } \\
\text { Controls }\end{array}$ & & & & * & * & * & * & * & & * \\
\hline & $\begin{array}{l}\text { (4) Defi- } \\
\text { nition of } \\
\text { Controls }\end{array}$ & & & & * & * & * & * & * & & * \\
\hline $\begin{array}{l}\text { Comparability: } \\
\text { (Maximum } 2 \\
\text { stars) }\end{array}$ & $\begin{array}{c}(5) \\
\text { Compa- } \\
\text { rability } \\
\text { of cases } \\
\text { and } \\
\text { controls } \\
\text { based on } \\
\text { the } \\
\text { design } \\
\text { or } \\
\text { analysis }\end{array}$ & $*$ & * & $*$ & * & $*$ & * & * & * & * & * \\
\hline \multirow{4}{*}{$\begin{array}{c}\text { Outcome: } \\
\text { (Maximum } 3 \\
\text { stars) }\end{array}$} & $\begin{array}{l}\text { (6) As- } \\
\text { certain- } \\
\text { ment of } \\
\text { expo- } \\
\text { sure }\end{array}$ & * & * & $*$ & * & $*$ & * & * & * & & * \\
\hline & $\begin{array}{l}\text { (7) Same } \\
\text { method } \\
\text { of ascer- } \\
\text { tain- } \\
\text { ment for } \\
\text { cases } \\
\text { and } \\
\text { controls }\end{array}$ & & & * & * & * & * & * & * & & * \\
\hline & $\begin{array}{l}\text { (8) Non- } \\
\text { Response } \\
\text { rate }\end{array}$ & * & $*$ & $*$ & & & & & & * & * \\
\hline & $\begin{array}{c}\text { Total } \\
\text { score }=\end{array}$ & 5 & 5 & 6 & 7 & 7 & 7 & 6 & 6 & 4 & 8 \\
\hline
\end{tabular}

* The answer is "yes" or it is described in the study. 
Table 5. Newcastle-Ottawa quality assessment scale cohort studies.

\begin{tabular}{|c|c|c|c|c|c|c|c|c|}
\hline & & $\begin{array}{c}\text { Scheer } \\
2016[36]\end{array}$ & $\begin{array}{c}\text { Farah } 2012 \\
{[30]}\end{array}$ & $\begin{array}{c}\text { Ganga } \\
2017[38]\end{array}$ & $\begin{array}{c}\text { Francisco } \\
2014[34]\end{array}$ & $\begin{array}{l}\text { Prajeesh } \\
2019 \text { [57] }\end{array}$ & $\begin{array}{l}\text { Epstein } \\
2003 \text { [58] }\end{array}$ & $\begin{array}{l}\text { Johnson } \\
2019 \text { [41] }\end{array}$ \\
\hline \multirow{4}{*}{$\begin{array}{c}\text { Selection: } \\
\text { (Maximum } 4 \\
\text { stars) }\end{array}$} & $\begin{array}{c}(1) \\
\text { Representa- } \\
\text { tiveness of } \\
\text { the } \\
\text { exposed } \\
\text { cohort }\end{array}$ & * & * & * & * & * & & * \\
\hline & $\begin{array}{l}(2) \\
\text { Selection of } \\
\text { the non- } \\
\text { exposed } \\
\text { cohort }\end{array}$ & * & * & $*$ & & * & * & \\
\hline & $\begin{array}{l}\text { (3) Ascer- } \\
\text { tainment of } \\
\text { exposure }\end{array}$ & * & * & * & * & * & * & * \\
\hline & $\begin{array}{l}\text { (4) Demon- } \\
\text { stration } \\
\text { that } \\
\text { outcome of } \\
\text { interest } \\
\text { was not } \\
\text { present at } \\
\text { the start of } \\
\text { the study }\end{array}$ & & & & & & & \\
\hline $\begin{array}{l}\text { Comparability: } \\
\text { (Maximum } 2 \\
\text { stars) }\end{array}$ & $\begin{array}{l}\text { (5) Compa- } \\
\text { rability of } \\
\text { cohorts } \\
\text { based on } \\
\text { the design } \\
\text { or analysis }\end{array}$ & * & * & * & * & * & * & * \\
\hline \multirow{4}{*}{$\begin{array}{c}\text { Outcome: } \\
\text { (Maximum } 3 \\
\text { stars) }\end{array}$} & $\begin{array}{l}\text { (6) Assess- } \\
\text { ment of } \\
\text { outcome }\end{array}$ & * & * & * & * & * & * & * \\
\hline & $\begin{array}{l}\text { (7) Was } \\
\text { follow-up } \\
\text { long } \\
\text { enough for } \\
\text { outcomes } \\
\text { to occur }\end{array}$ & * & * & * & & & * & * \\
\hline & $\begin{array}{c}\text { (8) } \\
\text { Adequacy } \\
\text { of follow } \\
\text { up of } \\
\text { cohorts }\end{array}$ & * & * & * & * & * & * & * \\
\hline & $\begin{array}{c}\text { Total } \\
\text { score }=\end{array}$ & 7 & 7 & 7 & 5 & 6 & 6 & 6 \\
\hline
\end{tabular}

* Described or available in the study. 
Comparison of techniques risk - sensitivity

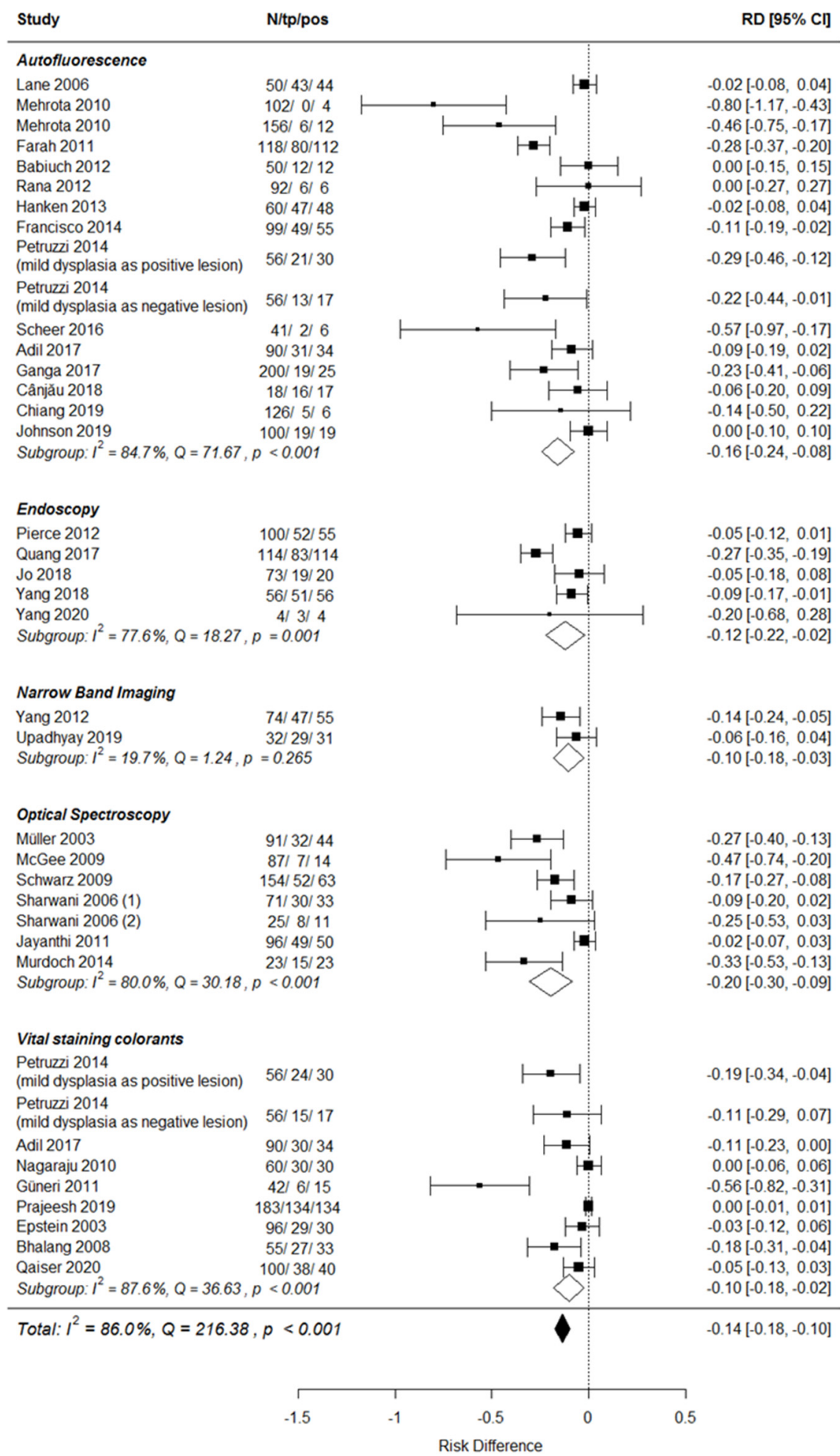

Figure 2. Comparison of studies.

\subsection{Consistency and Publication Bias}

Heterogeneity is significant at $p \leq 0.001$ level in all studies and all but a very small NBI group. From $77.6 \%$ of the variability in the HRME group to $87.6 \%$ in the vital staining colorants group come from heterogeneity. Consistency in the NBI group should be taken 
cautiously because the Q-based test is known to be poor at detecting true heterogeneity when the number of studies is small [81].

Funnel plot (Figure 3) shape suggests publication bias-results with larger risk difference having more chances to be published even if standard error is significant (i.e., number of positives is small).

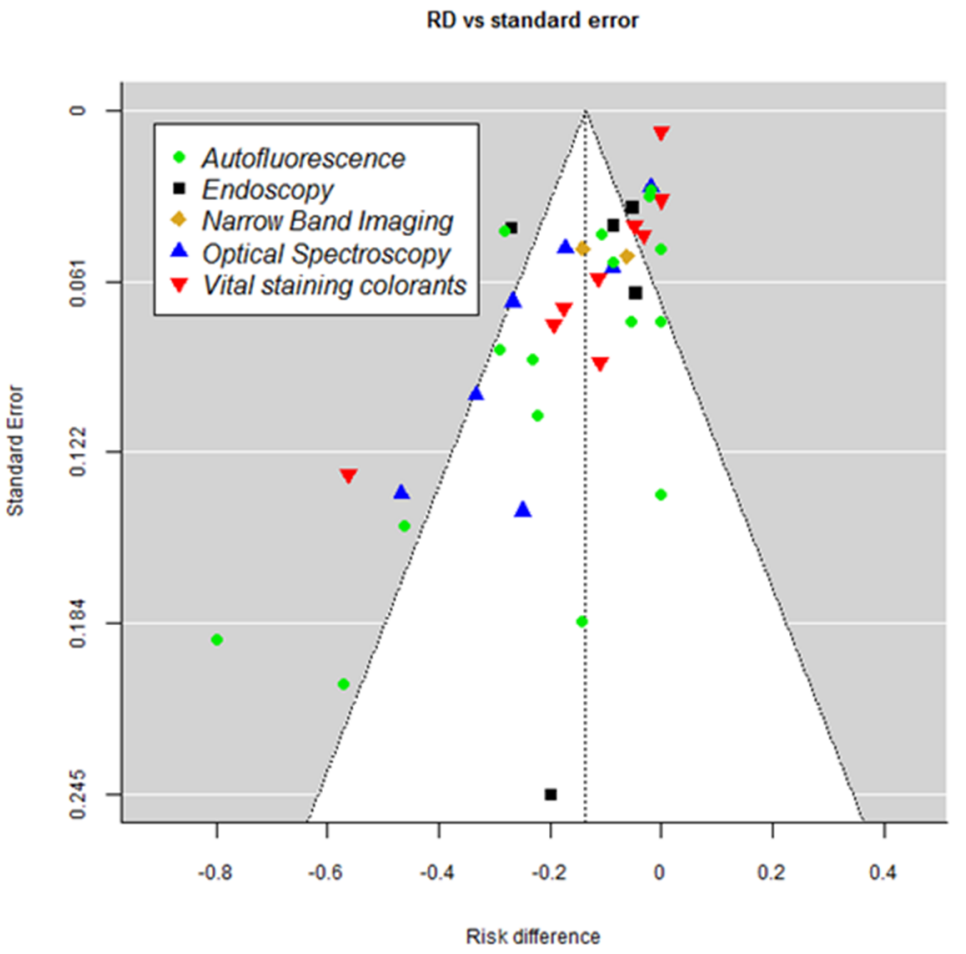

Figure 3. Funnel plot.

\subsection{Summarizing Findings}

Calculations showed:

- $\quad$ Using of techniques has a small negative effect size in sensitivity compared to biopsy. There are no significant differences in risk difference between techniques.

- $\quad$ Results are inconsistent both in the whole and in technique groups.

- $\quad$ Evidence of publication bias was also detected by analyzing funnel plot.

- Results reporting is not homogeneous across studies, which makes it challenging to carry out a reliable comparison of measures like specificity or positive/negative predictive values.

\section{Discussion}

The current systematic review and meta-analysis reported on the sensitivity of in vivo imaging-based techniques for early diagnosis of potentially malignant oral lesions (OPMDs) versus biopsy, which is considered the gold standard. The results showed that using of techniques has a small negative effect size in all five groups: from-0.10 in NBI and vital staining colorants groups to- -20 in the optical spectroscopy group. Studies with a lower sampling number showed worse results. With larger sample sizes, sensitivity also increased. The overall meta-analysis, however, reported a small negative effects size $(-0.14 ;-0.18$; $-0.10 ; 95 \% \mathrm{CI}$ ) of these techniques when compared to histopathology.

Oral screening is the first stage of early diagnosis: it can avoid delayed referrals and therefore reduce the mortality of SCC. It has been reported that SCC may develop from an OPMD, and its diagnosis is an important preventive step with significant consequences on patient survival rate and quality of life. The major limitation of visual inspection is the 
difficulty differentiating between benign, high-risk lesions and other mucosal diseases and conditions in the oral cavity [82,83].

Tissue biopsy is still considered as a gold standard for SCC diagnosis, however, it is invasive, time-consuming, painful, operator dependent, not easily acceptable by patients, especially by those with prior history of cancer, and available mainly in the hospital settings despite the need for oral screening to be widely performed in the private dental practices daily [4]. In fact, most SCCs tend to arise during the first two years after the detection of an OPMD, but several follow-up studies show that the risk may last up to 10-15 years. Therefore, managing these conditions may require regular and long-term follow-up and repeated diagnostic procedures by an experienced oral health professional. Erythroplakia, erythroleukoplakia, proliferative verrucous leukoplakia, and oral submucous fibrosis present with high malignant transformation risk that is lower in leukoplakia and oral lichen planus [4,84].

Diagnostic imaging-based techniques claim for higher acceptability by patients, low invasiveness, immediate results, repeatable assessments, and are suitable for regular followup and availability in the private practice setting and to be non-operator dependent. Some of these techniques are already commercially available, such as Vizilite and VelScope, and their accessibility also depends on the possibility to be purchased from health facilities, even by smaller ones. Moreover, these techniques reflect the current trend in healthcare toward artificial intelligence that can successfully transform medical images analysis in pathology, radiology and other fields of medical imaging [85-87]. A review published in 2018 by Yang et al. [45] on noninvasive diagnostic adjuncts for OPMDs evaluation showed that these techniques presented poor diagnostic accuracy due to high false-positive results [45]. Therefore, the current systematic review included studies published in the last fifteen years (2006-2020) to evaluate these techniques' further development, clinical applications and possible improvement/amelioration.

Starting with the best performance, NBI and Vital Staining colorants were characterized by a $-0.10 \mathrm{RD}$ and $(-0.18,-0.03)$ and $(-0.18,-0.02) 95 \% \mathrm{CI}$, respectively. The group of NBI accounted for two studies published in 2019 and 2012 [53,54]. In the study by Yang et al. [54], the total sample size was 74 sites with biopsy and 74 with NBI. The sensitivity and specificity were $84.62 \%$ and $94.56 \%$, respectively [53]. The sample size in the study by Upadhyay was 32 sites with biopsy and 32 with NBI, and the sensitivity and specificity resulted in $93.93 \%$ and $80 \%$ [54]. Our data agree with a recent meta-analysis aiming to describe the validity of NBI in the assessment of suspicious oral lesions demonstrated a specificity and sensitivity of $75.7 \%$ with $95 \%$ CI $65.1-83.9 \%$ and $91.5 \%$ with $95 \%$ CI $81.8-96.3 \%$, respectively [88]. The meta-analysis authors concluded that NBI could play a decisive role in a surveillance setting for low-risk lesions or lesions for which multiple biopsies may not be practical. Within higher-powered prospective studies with the establishment of precise clinical recommendations, the full potential of NBI both in the screening and tertiary referral setting could then be realized.

The vital staining colorants group evaluated the sensitivity in diagnosing OPMDs in 8 studies, published between 2008 and 2020, for a total sample size of 536 sites evaluated twice (Vsc vs. biopsy). Only data on sensitivity was reported in all the trials, while specificity only by three on them. The lowest sensitivity was shown in the study by Bhalang et al. [59] that evaluated the application of acetic acid in a group of 30 participants. This study scored seven in the quality assessment with the Newcastle-Ottawa scale adapted for cross-sectional studies [59]. The authors concluded that the results were promising, and the acetic acid was conveniently obtainable at any market despite the other colorants such as toluidine blue and recommended its use especially for oral screening in rural communities. Toluidine blue was the most frequently used colorant, and its best sensitivity performance was $92.3 \%$ in the study by Güneri et al. [56] aiming to evaluate toluidine blue, oral brush cytology, and biopsy in a group of 35 subjects and 43 oral lesions [56]. The results showed that Toluidine blue is a noninvasive method that offers real-time clinical information that may aid in completing a biopsy, biopsy site selection, and referral, in 
contrast to brush cytology, which requires specimen collection and a laboratory procedure. The absolute result was obtained by Fluorescein dye in the study conducted in 2020 by Qaiser et al. [60], with $95 \%$ of sensitivity. Fluorescein has been tested for the very first time for oral diagnosis of OPMDs, while it has been previously used for cancer diagnosis in the stomach, colon, breast, and brain [60]. The study was conducted at a tertiary care dental center and included 100 individuals. The dye is of organic origin, yellow, hypoallergenic, and nontoxic for topical use and produces an intense green-fluorescence in slightly acid to alkaline solutions. The study concluded that Fluorescein is an affordable and accessible technique, and it may find a promising role in community-based screening programs for oral cancer, especially in low- and middle-income regions, due to it being a safe and cost-effective measure $[60,89]$.

It is noticeable that OSCC is the most commonly reported malignancy in Southeast Asia for the highest cancer mortality, according to the GLOBOCAN 2018 [90]. Recent global estimates have revealed an annual incidence of 246,420 males and 108,444 females being registered worldwide.

The highest incidence rates for oral cancer are found in Southeast Asia, including the Indian subcontinent [90]. Currently, a distinct imbalance exists with regard to the oral cancer burden between the developed and the developing countries. This imbalance needs to be corrected $[90,91]$, and it partly accounts for the design of the included studies involving the research from Southeast Asia and the Indian subcontinent.

The autofluorescence subgroup was the most numerous, with a total of 15 included studies being published between 2006 and 2019. The reported risk difference was -0.16 (95\% CI-0.24-0.08). Vizilite, VELscope ${ }^{\circledR}$, Autofluorescence, fluorescence, and fluorescence spectroscopy were included in this subgroup. VELscope ${ }^{\circledR}$ was analyzed by nine studies, with a sensitivity ranging from $50 \%$ to $100 \%$. In the study by Babiuch et al. VELscope ${ }^{\circledR}$ showed a sensitivity and specificity for the detection of a dysplastic and cancer lesion of $100 \%$ and $12.5 \%$, respectively, demonstrating that VELscope ${ }^{\circledR}$ is useful in the detection of oral lesions, but not able to differentiate high risk and low-risk lesions [31]. The study by Rana et al. [32] showed excellent test results of $100 \%$ for the specificity of the device, but $74 \%$ for the specificity, explained by the fact that the study population consisted of patients with different histologic diagnoses and not only by high-risk patients with a former oral cancer diagnosis. The conclusions clearly underlined that VELscope ${ }^{\circledR}$ cannot replace biopsy but could help detect the right location for the procedure [32]. Then, although many widely recognized organizations as FDA and WHO approved VELscope ${ }^{\circledR}$ as a diagnostic tool for premalignant alternations and oral carcinoma, many researchers remain wary by stating that autofluorescence detecting devices can only act as an adjuvant and cannot be used as a confirmatory test in the diagnosis of oral cancer [92]. Moreover, as the study by Rana et al. [32] demonstrated, the device used by unskilled examiners could lead to high false-positive results due to misinterpretation of the test. In addition, Amirchaghmaghi et al. [93] stated that this device should not be used at a screening stage, as the high probability of false-positive results may cause a high unnecessary referral rate and unnecessary biopsies [93].

ViziLite is based on chemiluminescence; it was first used in the cervix to detect dysplasia and was recently adapted for examination of the oral mucosa. The device is easy to use, does not require consumable reagents, and provides real-time results. On the other hand, VizLite needs a dark environment, has high recurrent costs especially problematic for low-income regions. It leaves no permanent record unless photographed, carries low specificity for dysplasia, results in high referral rate and over-treatment, and is unable to detect some red lesions. The study by Mehrota et al. [29] reported a specificity of 75.5\%, and the authors concluded that ViziLite does not have the ability to accurately classify OPMDs by discriminating between high-risk and low-risk lesions and therefore should be used with caution. Moreover, since it is not able to detect some red lesions, it is reasonable to suggest that ViziLite assessments be interpreted in conjunction with the clinical findings [29]. The discussion on the risk of bias among the studies in the Autofluorescence aligns well with the 
recent systematic review of the bias found within studies evaluating the autofluorescence to detect OPMDs and OSCC, conducted by Tiwari et al. [92]. Among others, unclear descriptions of inclusion and exclusion criteria and small sample size were listed [94].

The high-resolution microscope (HRME) subgroup analyzed the data from five studies published from 2012 to 2020 . The RD was -0.12 with $95 \% \mathrm{CI}-0.22,-0.02$. Two studies were carried out by Yang et al. in 2018 and have demonstrated that the combined approach of autofluorescence (AFI) and high-resolution microscope (HRME), defined as multimodal imaging, showed higher accuracy than either modality alone, with $91 \%$ sensitivity in diagnosing OPMDs and OSCC [45,46]. Autofluorescence is noninvasive, macroscopic imaging of mucosa, showing high sensitivity for the detection of dysplasia and cancer, based on loss of fluorescence; however, benign lesions frequently gave a similar appearance to the dysplastic lesions by showing loss of fluorescence due to stroma; inflammation, thus leading to false positives [95]. HRME is a flexible fibre-optic fluorescence microscope that can image nuclear features of dysplasia such as nuclear to cytoplasm (NC) ratio and nuclear crowding using the topical contrast agent proflavine. Although HRME images have improved specificity even in the presence of stromal inflammation, it has a $<1 \mathrm{~mm}$ field of view, which poses difficulty in assessing entire lesions [42,43,62]. Hence it would be more appropriate for multimodal imaging where clinicians could exploit the different modalities of imaging based on its indications and advantages.

In 2018, Yang et al. [45] concluded that AFI and HRME could be used in an integrated manner for large suspicious lesions such that AFI first aids in the detection of the high-risk site within a large lesion followed by HRME imaging so that the entire lesion can be assessed for selecting the biopsy site [45]. This multimodal imaging can be effectively employed for community screening, thereby facilitating early detection and the reduction of oral cancer burden [45]. In 2020 Yang et al. carried out the subsequent clinical study and demonstrated that multimodal optical imaging identified more cases of high-grade dysplasia than clinical evaluation alone, but also indicated that a negative result in a high-risk population may not be a sufficient justification to avoid a clinically indicated biopsy [46]. The studies by Yang et al. reflected the status of multimodal optical imaging as an emerging technology that requires additional fine-tuning, further elucidation of its role in patient care, and randomized studies with larger sample sizes. More broadly, the optimal role of the MMIS has yet to be determined [46].

The optical spectroscopy subgroup in the meta-analysis of data shows RD- 0.20 and 95\% CI -0.30-0.09. The included studies were published between 2003 and 2014, with sensitivity ranging from $53 \%$ [50] to $98.5 \%$ [53]. Jayanthi et al., despite the good results, stated that large, prospective clinical studies are needed to reliably evaluate the efficacy of spectroscopy for these applications [51].

The diagnosis of oral cancer requires procedures with proven sensitivity and specificity, which are operator-independent and can be repeated in cases where high-risk patients require a long follow-up period. Data reported in this review are based on different techniques with high heterogeneity in study design, inclusion criteria, staging of disease and grading of differentiation (from $77.6 \%$ of the variability in the HRME group to $87.6 \%$ in vital staining colorants group come from heterogeneity). Therefore, prospective clinical trials reporting more homogeneous characteristics are needed. Moreover, diagnostic procedures must be adapted to national health systems, especially in those socio-political and economic macro areas characterized by fragility and difficulties in organizing and training highly qualified personnel. Thus, supporting research in underdeveloped countries can provide an opportunity to identify a technique with good clinical outcomes and low costs.

\section{Limitations}

The limitations are mainly due to the variable number of studies included for each analyzed technique, ranging from a minimum of 2 (NBI) to a maximum of 14 studies (Autofluorescence). In addition, heterogeneity was significant at the $p \leq 0.001$ level in 
all included studies, while the funnel plot showed publication bias. Moreover, the high percentage of variation resulted from the heterogeneity of the samples among the studies.

\section{Conclusions}

In conclusion, based on this systematic review and meta-analysis, none of the here analyzed techniques based on assessing oral images can replace the biopsy that remains the gold standard in the diagnosis of OPMDs and OSCC. However, according to the promising results obtained with NBI studies, further research is needed to explore the role of other techniques based on AI and imaging analysis to identify an early noninvasive screening method.

Author Contributions: Conceptualization, M.M.; Methodology, A.N.; Software, M.J. and C.A.; Validation, M.R. and L.O.; Formal Analysis, M.M. and G.T.; Investigation, A.N. and M.J.; Data Curation, C.A.; Writing_-Original Draft Preparation, D.C.V. and M.R.; Writing—Review \& Editing, M.M.; Visualization, G.T.; Supervision, F.G. and I.V.; Project Administration, L.O. and S.T. All authors have read and agreed to the published version of the manuscript.

Funding: This research did not receive any specific grant from funding agencies in the public, commercial, or not-for-profit sectors.

Institutional Review Board Statement: Not applicable.

Informed Consent Statement: Not applicable.

Data Availability Statement: The results of the search are available under URL.

Conflicts of Interest: The authors declare no conflict of interest.

\section{References}

1. Rao, N.R.; Villa, A.; More, C.B.; Jayasinghe, R.D.; Kerr, A.R.; Johnson, N.W. Oral submucous fibrosis: A contemporary narrative review with a proposed inter-professional approach for an early diagnosis and clinical management. Otolaryngol. Head Neck Surg. 2020, 49, 3. [CrossRef] [PubMed]

2. Gupta, P.C.; Warnakulasuriya, S. Global epidemiology of areca nut usage. Addict. Biol. 2002, 7, 7-83. [CrossRef]

3. Srinivasan, M.; Jewell, S.D. Evaluation of TGF-alpha and EGFR expression in oral leukoplakia and oral submucous fibrosis by quantitative immunohistochemistry. Oncology 2001, 61, 284-292. [CrossRef] [PubMed]

4. Warnakulasuriya, S. Oral potentially malignant disorders: A comprehensive review on clinical aspects and management. Oral. Oncol. 2020, 102, 104550. [CrossRef]

5. Warnakulasuriya, S.; Johnson, N.; VanderWaal, I. Nomenclature and classification of potentially malignant disorders of the oral mucosa. J. Oral Pathol. Med. 2007, 36, 575-580. [CrossRef] [PubMed]

6. Borse, V.; Konwar, A.N.; Buragohain, P. Oral cancer diagnosis and perspectives in India. Sens. Int. 2020, 1, 100046. [CrossRef]

7. Singh, M.; Prasad, C.P.; Singh, T.D.; Kumar, L. Cancer research in India: Challenges \& opportunities. Ind. J. Med. Res. 2018, 148, 362-365. [CrossRef]

8. Chinn, S.B.; Myers, J.N. Oral cavity carcinoma: Current management, controversies, and future directions. J. Clin. Oncol. 2015, 33, 3269-3276. [CrossRef] [PubMed]

9. Sarode, G.S.; Sarode, S.C.; Maniyar, N.; Sharma, N.; Yerwadekar, S.; Patil, S. Recent trends in predictive biomarkers for determining malignant potential of oral potentially malignant disorders. Oncol. Rev. 2019, 13, 424. [CrossRef]

10. Schwarz, R.; Gao, W.R.; Kurachi, C.; Lee, J.; El-Naggar, A.; Richards-Kortum, R.; Gillenwater, A. Noninvasive evaluation of oral lesions using depth-sensitive optical spectroscopy. Cancer 2009, 115, 1669-1679. [CrossRef]

11. Liu, D.; Zhao, X.; Zeng, X.; Dan, H.; Chen, Q. Non-invasive techniques for detection and diagnosis of oral potentially malignant disorders. Tohoku J. Exp. Med. 2016, 238, 165-177. [CrossRef] [PubMed]

12. Porter, S.; Gueiros, L.A.; Leão, J.C.; Fedele, S. Risk factors and etiopathogenesis of potentially premalignant oral epithelial lesions. Oral Surg. Oral Med. Oral Pathol. Oral Radiol. 2018, 125, 603-611. [CrossRef] [PubMed]

13. Becker, A.S.; Marcon, M.; Ghafoor, S.; Wurnig, M.C.; Frauenfelder, T.; Boss, A. Deep learning in mammography: Diagnostic accuracy of a multipurpose image analysis software in the detection of breast cancer. Investig. Radiol. 2017, 52, 434-440. [CrossRef] [PubMed]

14. Esteva, A.; Kuprel, B.; Novoa, R.A.; Ko, J.; Swetter, S.M.; Blau, H.M.; Thrun, S. Dermatologist-level classification of skin cancer with deep neural networks. Nature 2017, 542, 115-118. [CrossRef]

15. Gulshan, V.; Peng, L.; Coram, M.; Stumpe, M.C.; Wu, D.; Narayanaswamy, A.; Venugopalan, S.; Widner, K.; Madams, T.; Cuadros, J.; et al. Development and validation of a deep learning algorithm for detection of diabetic retinopathy in retinal fundus photographs. Am. Med. Assoc. 2016, 316, 2402-2410. [CrossRef] [PubMed] 
16. Schwendicke, F.; Golla, T.; Dreher, M.; Krois, J. Convolutional neural networks for dental image diagnostics: A scoping review. J. Dent. 2019, 91, 103226. [CrossRef] [PubMed]

17. Askar, H.; Krois, J.; Rohrer, C.; Mertens, S.; Elhennawy, K.; Ottolenghi, L.; Mazur, M.; Paris, S.; Schwendicke, F. Detecting white spot lesions on dental photography using deep learning: A pilot study. J. Dent. 2021, 107, 103615. [CrossRef]

18. Jitender, S.; Sarika, G.; Varada, H.R.; Omprakash, Y.; Mohsin, K. Screening for oral cancer. J. Exp. Ther. Oncol. $2016,11,303-307$.

19. Nagi, R.; Reddy-Kantharaj, Y.B.; Rakesh, N.; Janardhan-Reddy, S.; Sahu, S. Efficacy of light based detection systems for early detection of orl cancer and oral potentially malignant disorders: Systematic review. Med. Oral Patol. Oral Cir. Bucal 2017, 21, $447-455$.

20. Ferlay, J.; Colombet, M.; Soerjomataram, I.; Mathers, C.; Parkin, D.; Piñeros, M.; Znaor, A.; Bray, F. Estimating the global cancer incidence and mortality in 018: GLOBOCAN sources and methods. Int. J. Cancer 2019, 144, 1941-1953. [CrossRef]

21. Chaturvedi, P.; Singh, A.; Chien, C.Y.; Warnakulasuriya, S. Tobacco related oral cancer. Br. Med. J. 2019, 365, 12142. [CrossRef]

22. American Cancer Society. Cancer Facts and Figures 2005; American Cancer Society: Atlanta, GA, USA, 2005.

23. Gupta, G.; Vujicic, M.; Munson, B.; Nasseh, K. Recent trends in the market for oral surgeons, endodontists, orthodontists, periodontists, and pediatric dentists. Am. Dent. Assoc. 2017. Available online: http://www.ada.org/ \{\}/media/ADA/Science\% 20and\%20Research/HPI/Files/HPIBrief_0217_1.pdf (accessed on 26 June 2021).

24. Higgins, J.; Green, S. Cochrane Handbook for Systematic Reviews of Interventions. 2011. Available online: http:/ / www.cochranehandbook.org/ (accessed on 23 June 2021).

25. Higgins, J.P.T.; Thompson, S.G. Quantifying heterogeneity in a meta-analysis. Stat. Med. 2002, 21, 1539-1558. [CrossRef] [PubMed]

26. Del Re, A.C. A practical tutorial on conducting meta-analysis in R. Quant. Meth. 2015, 11, 37-50. [CrossRef]

27. Viechtbauer, W. Conducting meta-analyses in $\mathrm{r}$ with the metaphor package. J. Stat. Softw. 2010, 36, 1-48. [CrossRef]

28. Lane, P.M.; Gilhuly, T.; Whitehead, P.; Zeng, H.; Poh, C.; Ng, S.; Williams, P.M.; Zhang, L.; Rosin, M.P.; MacAulay, C. Simple device for the direct visualization of oral-cavity tissue fluorescence. J. Biomed. Opt. 2006, 11, 024006. [CrossRef] [PubMed]

29. Mehrotra, R.; Singh, M.; Thomas, S.; Nair, P.; Pandya, S.; Nigam, N.; Shukla, P. A cross-sectional study evaluating chemiluminescence and autofluorescence in the detection of clinically innocuous precancerous and cancerous oral lesions. Am. Dent. Assoc. 2010, 141, 151-156. [CrossRef]

30. Farah, C.S.; McIntosh, L.; Georgiou, A.; McCullough, M.J. Efficacy of tissue autofluorescence imaging (VELScope) in the visualization of oral mucosal lesions. Head Neck 2012, 34, 856-862. [CrossRef]

31. Babiuch, K.; Chomyszyn-Gajewska, M.; Wyszyńska-Pawelec, G. The use of VELscope ${ }^{\circledR}$ for detection of oral potentially malignant disorders and cancers-A pilot study. J. Biomed. Sci. 2012, 26, 11-16. [CrossRef]

32. Rana, M.; Zapf, A.; Kuehle, M.; Gellrich, N.C.; Eckardt, A.M. Clinical evaluation of an autofluorescence diagnostic device for oral cancer detection: A prospective randomized diagnostic study. Eu. J. Cancer Prev. 2012, 21, 460-466. [CrossRef]

33. Hanken, H.; Kraatz, J.; Smeets, R.; Heiland, M.; Assaf, A.; Blessmann, M.; Eichhorn, W.; Clauditz, T.S.; Gröbe, A.; Kolk, A.; et al. The detection of oral pre- malignant lesions with an autofluorescence based imaging system (VELscope ${ }^{\mathrm{TM}}$ )—A single blinded clinical evaluation. Head Face Med. 2013, 9, 1-7.

34. Francisco, A.; Correr, W.; Azevedo, L.; Kern, V.; Pinto, C.; Kowalski, L.; Kurachi, C. Fluorescence spectroscopy for the detection of potentially malignant disorders and squamous cell carcinoma of the oral cavity. Photodiagn. Photodyn. Ther. 2014, 11, 82-90. [CrossRef] [PubMed]

35. Petruzzi, M.; Lucchese, A.; Nardi, G.; Lauritano, D.; Favia, G.; Serpico, R.; Grassi, F.R. Evaluation of autofluorescence and toluidine blue in the differentiation of oral dysplastic and neoplastic lesions from non dysplastic and neoplastic lesions: A cross-sectional study. Biomed. Opt. 2014, 19, 76003. [CrossRef] [PubMed]

36. Scheer, M.; Fuss, J.; Derman, M.; Kreppel, M.; Neugebauer, J.; Rothamel, D.; Drebber, U.; Zoeller, J.E. Autofluorescence imaging in recurrent oral squamous cell carcinoma. Maxillofac. Surg. 2016, 20, 27-33. [CrossRef]

37. Adil, H.A.; Yuwanati, M.; Singh, A.; Sawant, S.; Umarji, H.R. Comparative study on the efficacy of tissue autofluorescence (visually enhanced lesion scope) and toluidine blue as a screening method in oral potentially malignant and malignant lesions. Med. Sci. 2017, 37, 91-96. [CrossRef]

38. Ganga, R.; Gundre, D.; Bansal, S.; Shirsat, P.; Prasad, P.; Desai, R. Evaluation of the diagnostic efficacy and spectrum of autofluorescence of benign, dysplastic and malignant lesions of the oral cavity using VELscope. Oral Oncol. 2017, 75, 67-74. [CrossRef]

39. Cânjău, S.; Sinescu, D.C.M.; Todea, C.; Pricop, M.O.; Duma, V.F. Fluorescence influence on screening decisions for oral malignant lesions. Rom. J. Morphol. Embryol. 2018, 59, 203-209.

40. Chiang, T.E.; Li, Y.C.; Lin, Y.H.; Wu, C.T.; Kuo, C.S.; Chen, Y.W. Comparative evaluation of autofluorescence imaging and histopathological investigation for oral potentially malignant disorders in Taiwan. Clin. Oral. Investig. 2019, 23, 2395-2402. [CrossRef]

41. Johnson, A.; Baeten, J.; Patel, K.K.; Sunny, S.; Suresh, A.; Uma, K.; Birur, P.; Kuriakose, M.; Kademani, D. Evaluation of a Lectin-Based Imaging System for the Chairside Detection of Oral Dysplasia and Malignancy. J. Oral Maxillofac. Surg. 2019, 77, 1941-1951. [CrossRef]

42. Pierce, M.; Schwarz, R.; Bhattar, V.; Mondrik, S.; Williams, M.; Lee, J.; Richards-Kortum, R.; Gillenwater, A. Accuracy of in vivo multimodal optical imaging for detection of oral neoplasia. Cancer Prev. Res. 2012, 5, 801-809. [CrossRef] 
43. Quang, T.; Tran, E.; Schwarz, R.; Williams, M.; Vigneswaran, N.; Gillenwater, A.; Richards-Kortum, R. Prospective evaluation of multimodal optical imaging with automated image analysis to detect oral neoplasia in vivo. Cancer Prev. Res. 2017, 10, 563-570. [CrossRef]

44. Jo, J.; Cheng, S.; Cuenca-Martinez, R.; Duran-Sierra, E.; Malik, B.; Ahmed, B.; Maitland, K.; Cheng, Y.-S.L.; Wright, J.; Reese, T. Endogenous fluorescence lifetime imaging (flim) endoscopy for early detection of oral cancer and dysplasia. Annu. Int. Conf. IEEE Eng. Med. Biol. 2018, 2018, 3009-3012.

45. Yang, E.; Schwarz, R.; Lang, A.; Bass, N.; Badaoui, H.; Vohra, I.; Cherry, K.D.; Williams, M.D.; Gillenwater, A.; Vigneswaran, N.; et al. In vivo multimodal optical imaging: Improved detection of oral dysplasia in low-risk oral mucosal lesions. Cancer Prev. Res. 2018, 11, 465-476. [CrossRef] [PubMed]

46. Yang, E.; Vohra, I.; Badaoui, H.; Schwarz, R.; Cherry, K.; Jacob, J.; Rodriguez, J.; Williams, M.D.; Vigneswaran, N.; Gillenwater, A.M.; et al. Prospective evaluation of oral premalignant lesions using a multimodal imaging system: A pilot study. Head Neck 2020, 42, 171-179. [CrossRef] [PubMed]

47. Müller, M.; Valdez, T.; Georgakoudi, I.; Backman, V.; Fuentes, C.; Kabani, S.; Laver, N.; Wang, Z.; Boone, C.W.; Dasari, R.R.; et al. Spectroscopic detection and evaluation of morphologic and biochemical changes in early human oral carcinoma. Cancer 2003, 97, 1681-1692. [CrossRef]

48. McGee, S.; Mardirossian, V.; Elackattu, A.; Mirkovic, J.; Pistey, R.; Gallagher, G.; Kabani, S.; Yu, C.-C.; Wang, Z.; Badizadegan, K.; et al. Anatomy based algorithms for detecting oral cancer using reflectance and fluorescence spectroscopy. Ann. Otol. Rhinol. Laryngol. 2009, 118, 817-826. [CrossRef]

49. Sharwani, A.; Jerjes, W.; Salih, V.; MacRobert, A.; El-Maaytah, M.; Khalil, H.; Hopper, C. Fluorescence spectroscopy combined with 5-aminolevulinic acid-induced protoporphyrin IX fluorescence in detecting oral premalignancy. J. Photochem. Photobiol. A 2006, 83, 27-33. [CrossRef]

50. Sharwani, A.; Jerjes, W.; Salih, V.; Swinson, B.; Bigio, I.; El-Maaytah, M.; Hopper, C. Assessment of oral premalignancy using elastic scattering spectroscopy. Oral Oncol. 2006, 42, 343-349. [CrossRef] [PubMed]

51. Jayanthi, J.; Nisha, G.; Manju, S.; Philip, E.; Jeemon, P.; Baiju, K.; Beena, V.T.; Subhash, N. Diffuse reflectance spectroscopy: Diagnostic accuracy of a non-invasive screening technique for early detection of malignant changes in the oral cavity. BMJ Open 2011, 1, e000071. [CrossRef]

52. Murdoch, C.; Brown, B.; Hearnden, V.; Speight, P.; D’Apice, K.; Hegarty, A.; Healey, J.; Highfield, P.; Tidy, J. Use of electrical impedance spectroscopy to detect malignant and potentially malignant oral lesions. Int. J. Nanomed. 2014, 9, 4521-4532. [CrossRef]

53. Yang, S.W.; Lee, Y.S.; Chang, L.C.; Hwang, C.C.; Chen, T.A. Diagnostic significance of narrow-band imaging for detecting high-grade dysplasia, carcinoma in situ, and carcinoma in oral leukoplakia. Laryngoscope 2012, 122, 2754-2761. [CrossRef] [PubMed]

54. Upadhyay, A.; Saraswathi, N.; Mundra, R.K. Narrow band imaging: An effective and early diagnostic tool in diagnosis of oral malignant lesions. Indian J. Otolaryngol. Head Neck Surg. 2019, 71, 967-971. [CrossRef] [PubMed]

55. Nagaraju, K.; Prasad, S.; Ashok, L. Diagnostic efficiency of toluidine blue with Lugol's iodine in oral premalignant and malignant lesions. Indian J. Dent. Res. 2010, 21, 218-223. [CrossRef] [PubMed]

56. Güneri, P.; Ergün, J.B.; Epstein, S.; Boyacioğlu, H. Toluidine blue color perception in identification of oral mucosal lesions. Clin. Oral Investig. 2011, 15, 327-335. [CrossRef] [PubMed]

57. Prajeesh, K.M.; Soni, S. A study of toluidine blue staining in suspected oral malignancies in patients presenting to tertiary care hospital in central india. Indian J. Otolaryngol. Head Neck Surg. 2019, 71, 492-497. [CrossRef] [PubMed]

58. Epstein, J.B.; Feldman, R.; Dolor, R.J.; Porter, S.R. The utility of tolonium chloride rinse in the diagnosis of recurrent or second primary cancers in patients with prior upper aerodigestive tract cancer. Head Neck 2003, 25, 911-921. [CrossRef]

59. Bhalang, K.; Suesuwan, A.; Dhanuthai, K.; Sannikorn, P.; Luangjarmekorn, L.; Swasdison, S. The application of acetic acid in the detection of oral squamous cell carcinoma. Oral Surg. Oral Med. Oral Pathol. Oral Radiol. 2008, 106, 371-376. [CrossRef]

60. Qaiser, D.; Sood, A.; Mishra, D.; Kharbanda, O.; Srivastava, A.; Gupta, S.; Pandey, R.; Yadav, R.; Bhatt, K.; Kumawat, R. Novel use of fluorescein dye in detection of oral dysplasia and oral cancer. Photodiag. Photodyn. Ther. 2010, 31, 101824. [CrossRef]

61. Awan, K.H.; Morgan, P.R.; Warnakulasuriya, S. Evaluation of an autofluorescence based imaging system (VELscope $\left.{ }^{\mathrm{TM}}\right)$ in the detection of oral potentially malignant disorders and benign keratoses. Oral Oncol. 2011, 47, 274-277. [CrossRef]

62. Muldoon, T.J.; Pierce, M.C.; Nida, D.L.; Williams, M.D.; Gillenwater, A.; Richards-Kortum, R. Subcellular-resolution molecular imaging within living tissue by fiber microendoscopy. Opt. Express 2007, 15, 16413-16423. [CrossRef]

63. Muldoon, T.J.; Anandasabapathy, S.; Maru, D.; Richards-Kortum, R. High-resolution imaging in Barrett's esophagus: A novel, low-cost endoscopic microscope. Gastroint. Endosc. 2008, 68, 737-744. [CrossRef]

64. Muldoon, T.J.; Roblyer, D.; Williams, M.D.; Stepanek, V.M.; Richards-Kortum, R.; Gillenwater, A.M. Noninvasive imaging of oral neoplasia with a high-resolution fiber-optic microendoscope. Head Neck 2012, 34, 305-312. [CrossRef] [PubMed]

65. Muto, M.; Nakane, M.; Katada, C.; Sano, Y.; Ohtsu, A.; Esumi, H.; Ebihara, S.; Yoshida, S. Squamous cell carcinoma in situ at oropharyngeal and hypopharyngeal mucosal sites. Cancer 2004, 101, 1375-1381. [CrossRef] [PubMed]

66. Muto, M.; Sano, Y.; Fujii, S.; Ochiai, A.; Yoshida, S. Endoscopic diagnosis of intraepithelial squamous neoplasia in head and neck and esophageal mucosal sites. Dig. Endosc. 2006, 18, S2-S5. [CrossRef] 
67. Sumiyama, K.; Kaise, M.; Nakayoshi, T.; Kato, M.; Mashiko, T.; Uchiyama, Y.; Goda, K.; Hino, S.; Nakamura, Y.; Matsuda, K.; et al. Combined use of a magnifying endoscope with a narrow band imaging system and a multibending endoscope for en bloc EMR of early-stage gastric cancer. Gastrointest. Endosc. 2004, 60, 79-84. [CrossRef]

68. Takano, J.H.; Yakushiji, T.; Kamiyama, I.; Nomura, T.; Katakura, A.; Takano, N.; Shibahara, T. Detecting early oral cancer: Narrowband imaging system observation of the oral mucosa microvasculature. Int. J. Oral Maxillofac. Surg. 2010, 39, 208-213. [CrossRef] [PubMed]

69. Li, Y.N.; Lu, R.; Zhang, J.; Zhou, G. Inter-and intra-observer agreement on the judgment of toluidine blue staining for screening of oral potentially malignant disorders and oral cancer. Clin. Oral Investig. 2019, 23, 1709-1714. [CrossRef] [PubMed]

70. Allegra, E.; Lombardo, N.; Puzzo, L.; Garozzo, A. The usefulness of toluidine staining as a diagnostic tool for precancerous and cancerous oropharyngeal and oral cavity lesions. Acta Otorhinolaryngol. Ital. 2009, 29, 187-190. [PubMed]

71. Patton, L.L.; Epstein, J.B.; Kerr, A.R. Adjunctive techniques for oral cancer examination and lesion diagnosis: A systematic review of the literature. J. Am. Dent. Assoc. 2008, 139, 896-994. [CrossRef] [PubMed]

72. Jayasinghe, R.D.; Hettiarachchi, P.; Amugoda, D.; Kumaraarachchi, M.; Liyanage, R.; Siriwardena, B.; Gunasena, R.; Karunatilake, A.; Amarasinghe, H. Validity of Toluidine Blue test as a diagnostic tool for high-risk oral potentially malignant disorders-A multicentre study in Sri Lanka. J. Oral Biol. Craniofac. Res. 2020, 10, 547-551. [CrossRef] [PubMed]

73. Ambele, A.; van Zyl, M.A.; Pepper, M.S.; van Heerden, M.B.; van Heerden, W.F.P. Amplification of 3q26.2, 5q14.3, 8q24.3, 8q22.3, and 14q32.33 Are Possible Common Genetic Alterations in Oral Cancer Patients. Front. Oncol. 2020, 10, 683. [CrossRef]

74. Ikeda, Y.; Suzuki, T.; Saitou, H.; Ogane, S.; Hashimoto, K.; Takano, N.; Nomura, T. Usefulness of fluorescence visualization-guided surgery for early-stage tongue squamous cell carcinoma compared to iodine vital staining. Int. J. Clin. Oncol. 2020, 25, 1604-1611. [CrossRef]

75. Poh, C.; Ng, S.; Williams, P.; Zhang, L.; Laronde, D.; Lane, P.; MacAulay, C.; Rosin, M.P. Direct fluorescence visualization of clinically occult high-risk oral premalignant disease using a simple hand-held device. Head Neck 2007, 29, 71-76. [CrossRef] [PubMed]

76. Fakurnejad, S.; van Keulen, S.; Nishio, N.; Engelen, M.; Berg, N.S.V.D.; Lu, G.; Birkeland, A.; Baik, F.; Colevas, A.D.; Rosenthal, E.L.; et al. Fluorescence molecular imaging for identification of high-grade dysplasia in patients with head and neck cancer. Oral Oncol. 2019, 97, 50-55. [CrossRef] [PubMed]

77. Poh, C.; Anderson, D.; Durham, J.; Chen, J.; Berean, K.; MacAulay, C.; Rosin, M.P. Fluorescence visualization-guided surgery for early-stage oral cancer. JAMA Otolaryng-Head Neck Surg. 2016, 142, 209-216. [CrossRef] [PubMed]

78. Huff, P.C.; Stark, K.; Solomon, L.W. Sensitivity of direct tissue fluorescence visualization in screening for oral premalignant lesions in general practice. Gen. Dent. 2009, 57, 34-38.

79. Mallia, R.; Subhash, N.; Sebastian, P.; Kumar, R.; Thomas, S.; Mathews, A.; Madhavan, J. In vivo temporal evolution of ALAinduced normalized fluorescence at different anatomical locations of oral cavity: Application to improve cancer diagnostic contrast and potential. Photodiagn. Photodyn. Ther. 2020, 7, 162-175. [CrossRef]

80. Vijayavel, T.; Aswath, N. Correlation between histological grading and ploidy status in potentially malignant disorders of the oral mucosa: A flow cytometric analysis. J. Oral Maxillofac. Pathol. 2013, 17, 169-175.

81. Cohen, J. Statistical Power Analysis for the Behavioral Sciences; Lawrence Erlbaum Associates: Mahwah, NJ, USA, 1988.

82. Wright, J.M.; Vered, M. Update from the 4th Edition of the World Health Organization Classification of Head and Neck Tumours: Odontogenic and Maxillofacial Bone Tumors. Head Neck Pathol. 2017, 11, 68-77. [CrossRef]

83. Scully, C.; Bagan, J.V.; Hopper, C.; Epstein, J.B. Oral cancer: Current and future diagnostic techniques. Am. J. Dent. 2008, 21, 199-209.

84. Duś-Ilnicka, I.; Radwan-Oczko, M.; Gerber, H.; Hałoń, A. Histopathological assessment of oral leukoplakia. Osteonectin as possible biomarker for further diagnostics. Pol. J. Pathol. 2020, 71, 138-145. [CrossRef]

85. Aubreville, M.; Knipfer, C.; Oetter, N.; Jaremenko, C.; Rodner, E.; Denzler, J.; Bohr, C.; Neumann, H.; Stelzle, F.; Maier, A.K. Automatic classification of cancerous tissue in laserendomicroscopy images of the oral cavity using deep learning. Sci. Rep. 2017, 7, 11979. [CrossRef] [PubMed]

86. Hassan, C.; Wallace, M.B.; Sharma, P.; Maselli, R.; Craviotto, V.; Spadaccini, M.; Repici, A. New artificial intelligence system: First validation study versus experienced endoscopists for colorectal polyp detection. Gut 2020, 69, 799-800. [CrossRef] [PubMed]

87. Duś-Ilnicka, I.; Szymczak, A.; Małodobra-Mazur, M.; Tokarski, M. Role of Laboratory Medicine in SARS-CoV-2 Diagnostics. Lessons Learned from a Pandemic. Healthcare 2021, 9, 915. [CrossRef] [PubMed]

88. Ansari, U.H.; Wong, E.; Smith, M.; Singh, N.; Palme, C.E.; Smith, M.C.; Riffat, F. Validity of narrow band imaging in the detection of oral and oropharyngeal malignant lesions: A systematic review and meta-Analysis. Head Neck 2019, 41, 2430-2440. [CrossRef] [PubMed]

89. Nardi, G.M.; Cesarano, F.; Papa, G.; Chiavistelli, L.; Ardan, R.; Jedlinski, M.; Mazur, M.; Grassi, R.; Grassi, F.R. Evaluation of Salivary Matrix Metalloproteinase (MMP-8) in Periodontal Patients Undergoing Non-Surgical Periodontal Therapy and Mouthwash Based on Ozonated Olive Oil: A Randomized Clinical Trial. Int. J. Environ. Res. Public Health 2020, $17,6619$. [CrossRef] [PubMed]

90. Bray, F.; Ferlay, J.; Soerjomataram, I.; Siegel, R.L.; Torre, L.A.; Jemal, A. Global cancer statistics 2018: GLOBOCAN estimates of incidence and mortality worldwide for 36 cancers in 185 countries. CA Cancer J. Clin. 2018, 68, 394-424. [CrossRef] 
91. Mazur, M.; Ndokaj, A.; Jedlinski, M.; Ardan, R.; Bietolini, S.; Ottolenghi, L. Impact of Green Tea (Camellia Sinensis) on periodontitis and caries. Systematic review and meta-analysis. Jpn. Dent. Sci. Rev. 2021, 57, 1-11. [CrossRef]

92. Balasubramaniam, A.; Sriraman, R.; Sindhuja, P.; Mohideen, K.; Parameswar, R.; Muhamed Haris, K. Autofluorescence based diagnostic techniques for oral cancer. J. Pharm. Bioallied Sci. 2015, 7, S374-S377. [CrossRef]

93. Amirchaghmaghi, M.; Mohtasham, N.; Delavarian, Z.; Shakeri, M.T.; Hatami, M.; Mosannen Mozafari, P. The diagnostic value of the native fluorescence visualization device for early detection of premalignant/malignant lesions of the oral cavity. Photodiagn. Photodyn. Ther. 2018, 21, 19-27. [CrossRef]

94. Tiwari, L.; Kujan, O.; Farah, C.S. Optical fluorescence imaging in oral cancer and potentially malignant disorders: A systematic review. Oral Dis. 2020, 26, 491-510. [CrossRef] [PubMed]

95. Pavlova, I.; Williams, M.; El-Naggar, A.; Richards-Kortum, R.; Gillenwater, A. Understanding the biological basis of autofluorescence imaging for oral cancer detection: High-resolution fluorescence microscopy in viable tissue. Clin. Cancer Res. 2008, 14, 2396-2404. [CrossRef] [PubMed] 